\title{
Research on Correction Method of Palatal Rugae Morphology in Forensic Digital Identification System
}

\author{
Investigación sobre el Método de Corrección de la Morfología de \\ las Rugas Palatinas en Sistema Digital de Identificación Forense
}

Hong Shangguan ${ }^{1}$;Li Bing²; Zhang Xiong ${ }^{1}$;Xin-Xin Ji ; Tae-Geon Kwon ${ }^{3}$ \& Xiu-Ping Wu ${ }^{2}$

SHANGGUAN, H.; LI, B.; ZHANG, X.; JI, X. X.; KWON, T. G. \& WU, X. P. Research on correction method of palatal rugae morphology in forensic digital identification system. Int. J. Morphol., 37(1):324-330, 2019.

SUMMARY: Palatal rugae is an irregular soft tissue, which is located in the front third of the hard palate, and is asymmetrically distributed from the middle suture to the sides. The difference, stability and extensive characteristics of palatal rugae morphology have gradually make it a characteristic indicator of forensic identification. However, a mature digital palatal rugae identification system has not yet been established at present. Feature extraction is the premise of palatal rugae image recognition. In order to obtain palatal rugae feature information in all directions and improve the reliability of forensic identification, it is necessary to collect palatal rugae images from a plurality of different angles. When the collected images are sent to the recognition system, the diversity of angles will often cause problems such as error recognition. If the tilted images are not rotated properly, it will make the forensic identification face many difficulties. To solve the problem of image skew caused by the diversity of acquisition angle, an algorithm based on orientation vector to correct the tilted palatal rugae images was proposed in this paper. Firstly, the criteria for standard palatal rugae image and the selection rules for feature points were set; Secondly, characterizing feature points according to the rules, and fitting two lines and find their direction vector; Finally, to obtain the corrected images, the tilted images were rotated by the angle determined by the two direction vectors. Simulation results show that the proposed algorithm can correct the tilted palatal rugae images collected from different angles and has strong robustness.

KEY WORDS: Forensic odontology; Palatal rugae; Forensic identification; Direction vector; Image correction.

\section{INTRODUCTION}

Forensic identification is a forensic comparison of the similarities and differences between two or more characteristic indicators of known and unknown objects to infer whether the object under study is from the same object. The characteristic indicators adopted in the forensic identification must satisfy the conditions of uniqueness, universality, permanence, collability and identifiability (Clarke, 1994; Jain et al., 2000, 2016). Palatal rugae is an irregular soft tissue, which is located in the front third of the hard palate, and is asymmetrically distributed from the middle suture to the sides (Indira et al., 2011; Syed et al., 2016). The universality, stability and uniqueness of the palatal rugae pattern meet the requirements of forensic identification and can be used as a characteristic indicator for forensic identification (Taneva et al., 2017; Gautam et al., 2017; Gadicherla et al., 2017). Compared with other relatively mature identification techniques (such as DNA), palatal rugae identity is still in the initial stage of study (Li et al., 2014; Wu et al., 2016). Scholars have focused on the description of the palatal rugae pattern and the coding of the rugaes (Bharath et al., 2011; Mittal et al., 2013; Braga \& Caldas, 2016). There are few ideal preprocessing and evaluation schemes about the palatal rugae images, and a more complete preprocessing system has not been established. The lack of the preliminary treatment scheme has increased the difficulty of the follow-up work. This study aims to improve the accuracy of palatal rugae image recognition through the study of the image correction method in the palatal rugae image preprocessing system.

\footnotetext{
${ }^{1}$ School of electronic information engineering, Taiyuan University of Science and Technology, Taiyuan, China.

${ }^{2}$ Department of Prosthodontics, School of Dentistry, Shanxi Medical University, Taiyuan, China.

${ }^{3}$ School of Dentistry, Kyungpook National University, Daegu, Korea.

FUNDING: Shanxi Province Science Foundation for Youths, No. 201701D221106.

Taiyuan University of Science and Technology doctoral promoter, No. 20162044.

The International Cooperation Project of Science and Technology Department of Shanxi Province(China - Korea),No. 201803D421062
} 


\section{MATERIAL AND METHOD}

Materials and instruments. Digital single reflector camera (Canon EOS 300D); Dental orthodontic special reflector; Photoshop image processing software; Matlab numerical computing software of American MathWorks company; SPSS13.0 statistics software.

Data acquisition. Using the single reflector camera (Canon EOS 300D), which is set the same parameters, fixed position and fixed focal length, to obtain the high resolution and of reference value intraoral palatal rugae images. The image processing software Photoshop is used to make a preliminary cutting process. The camera is equipped with specially customized equipment to make the image standard unified. The image is transmitted to the computer in JPEG format, and all palatal rugae pictures are utilized to build a database.

\section{Standard image definition and Feature point selection.} The incisive papilla is used as the midpoint, and the feature points are selected at the approximate midpoint of the contour of the third tooth on the left and right sides, and are selected in order from left to right. If the two-point connection is a horizontal line, the palatal rugae image is a standard image, and this state is a standard state. If twopoint connection is a non-horizontal line, it is a non-standard image and needs to be corrected. As shown in Figure 1 , the '*' points are the selected feature points, which are located in the approximate midpoint position of the third

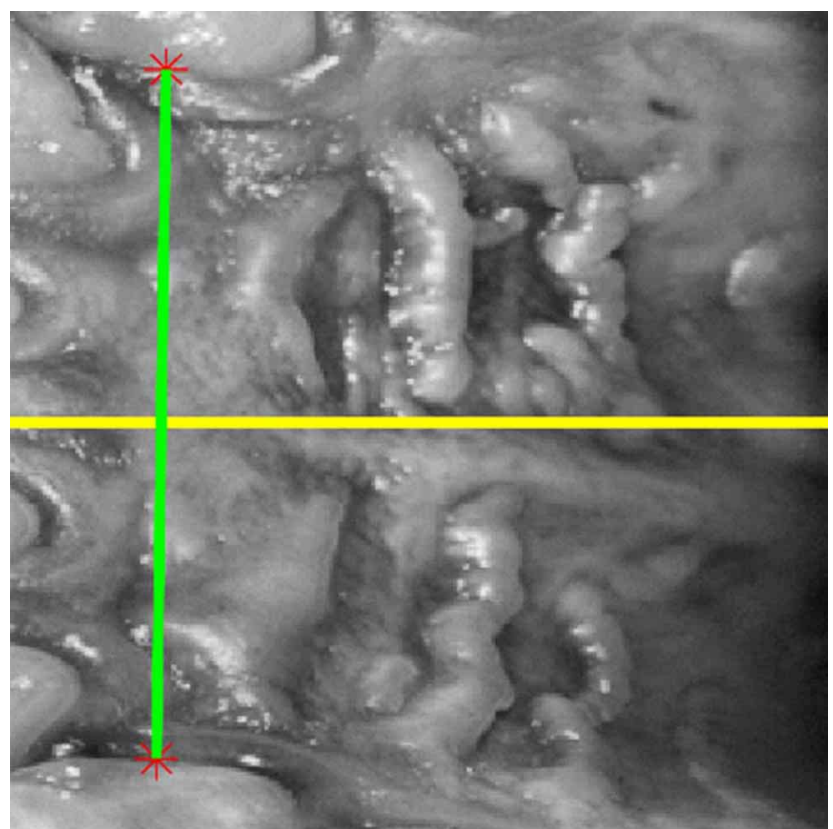

Fig. 1. Schematic diagram of non-standard palatal rugae image. tooth on the left and right sides, and the yellow line is the reference horizontal line connected by the predetermined point. The green line is connected by the two selected feature points. The angle between the green line and the reference line is about $90^{\circ}$, indicating that the feature point connection line in the figure is not a horizontal line, so the palatal rugae image is a non-standard image.

Determination of tilt angle. The key point to the correction of tilted images lies in the determination of tilt direction and tilt angle. The tilt angle was determined by the two-point method in this research.

(1) Determine the line $L_{1}$ formed by the two preset points and its direction vector $S_{1}$. The two ends of the linear $L_{1}$ are $\left(x_{0}, y_{0}\right)=(1, n / 2)$ and $\left(x_{1}, y_{1}\right)=(m / 2, n / 2) . m$ is the width of the palatal wrinkle image, and $n$ is the height of the palatal wrinkle image. The increment of the $x$ direction is $\mathrm{t}_{\mathrm{x}}=x_{1}$ $x_{0}$. The increment of the $y$ direction is $t_{y}=y_{1}-y_{0}$. The direction vector of $L_{1}$ is $S_{1}=\left(t_{\mathrm{x}}, t_{\mathrm{y}}\right)$.

(2) Determine the line $L_{2}$ formed by the two correction feature points and its direction vector $S_{2}$. In this study, the coordinates $\left(x_{2}, y_{2}\right)$ and $\left(x_{3}, y_{3}\right)$ of two feature points are automatically read into the image. Fitting the line $L_{2}$ by the least square method, and the increment of the $x$ direction is $s_{\mathrm{x}}=x_{3}-x_{2}$. The increment of the $y$ direction is $s_{\mathrm{y}}=y_{3}$ $\left.y_{2}\right)$. And find the direction vector $S_{2}=\left(s_{x}, s_{y}\right)$ of the straight line $L_{2}$.

(3) Calculate the tilt angle. The tilt angle $v$ is the angle between the direction vectors $S_{1}$ and $S_{2} \cdot v$ can be calculated by the following formulas. A schematic diagram of the solution process is shown in Figure 2.

$$
\begin{gathered}
l=\frac{s_{1} \cdot s_{2}}{\left\|s_{1}\right\| \cdot\left\|s_{2}\right\|} \\
s_{1} \cdot s_{2}=t_{x} \cdot s_{x}+t_{y} \cdot s_{y} \\
a=\left\|S_{1}\right\|=\sqrt{t_{x}^{2}+t_{y}^{2}} \\
b=\left\|S_{2}\right\|=\sqrt{s_{x}^{2}+s_{y}^{2}} \\
v=\cos ^{-1} l
\end{gathered}
$$




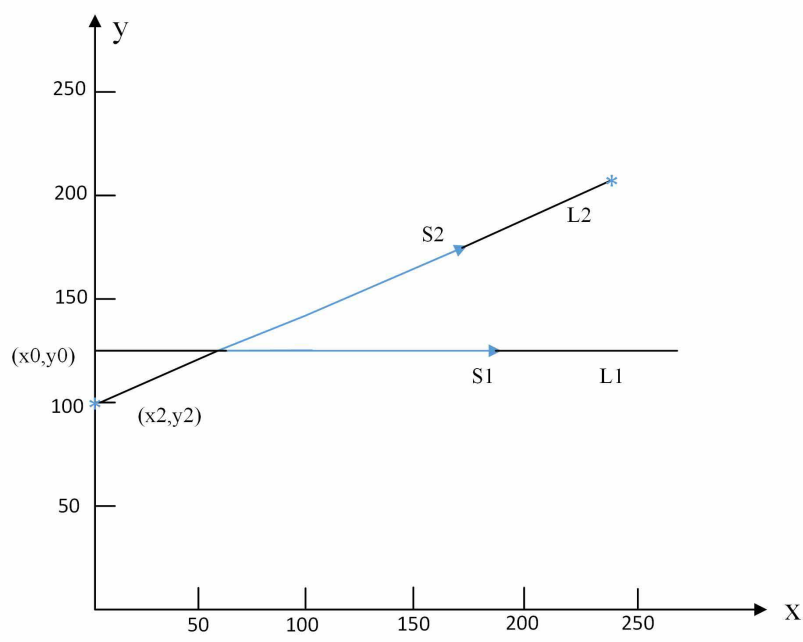

Fig. 2. Schematic diagram of the tilt angle solution process.

Determination of rotation direction. Based on the definition of standard palatal rugae image, the tilt pattern of palatal rugae image can be divided into two types (as shown in Figure 3). The chord area in Figure 3 represents the palatal rugae. According to the coordinates of the selected feature points, the relative positions are compared, and the direction of rotation can be determined by the distribution of the feature points in the image. That is, for the selected feature point coordinates $\left(x_{2}, y_{2}\right)$ and $\left(x_{3}, y_{3}\right)$, the size of $y_{2}$ and $y_{3}$ are compared. When , $y_{2}<y_{3}$ it is the first tilting mode. At this time, the image should be rotated clockwise at $v$. When $y_{2} \geq$ $y_{3}$, it is the second tilting mode. At this time, the image should be rotated counter clockwise at $v$.
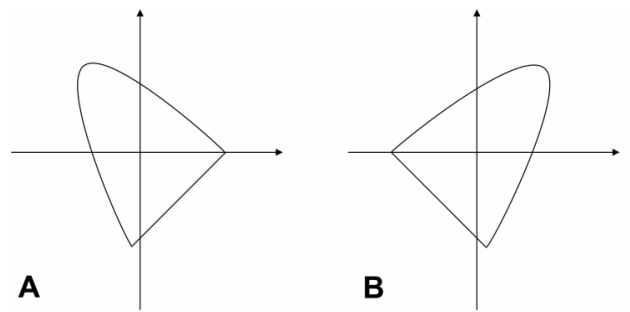

Fig. 3. Schematic diagram of the two kinds of tilting patterns. (A) Tilt pattern 1 (B) Tilt pattern 2.
Process of image correction. Figure 4 shows a schematic diagram of the correction process of a tilting palatal rugae image. The incisive papilla is the area marked by the red circle in Figure 4(A). It can be observed that the incisive papilla of the original image faces the left side, which is about 90 degrees different from the defined standard state. According to the rules, the feature points are selected at the middle point of the third teeth on the two sides of the incisive papilla. As shown in Figure 4(B), the rotation angle can be calculate by the line connected by the feature points and the line connected by the presetting points. The standard image can be obtained by rotating the angle clockwise, as shown in Figure 4(C).

Simulation experiment and analysis. Rotate an ordinary palatal rugae image to a standard state, and then rotate the standard image 5 degrees and 12 degrees respectively ( as shown in Figure 5). The linear interpolation algorithm is used to interpolate the gray level to get two tilted images with known fixed inclination angles. The proposed algorithm is used to perform six corrections on two tilted palatal rugae images. Figures 6 and 7 show the six corrected images of 5 degrees and 12 degrees tilted palatal rugae images. Each correction point selects the same location as the same value. The corrected image is compared with its standard image to test the effectiveness and stability of the algorithm.
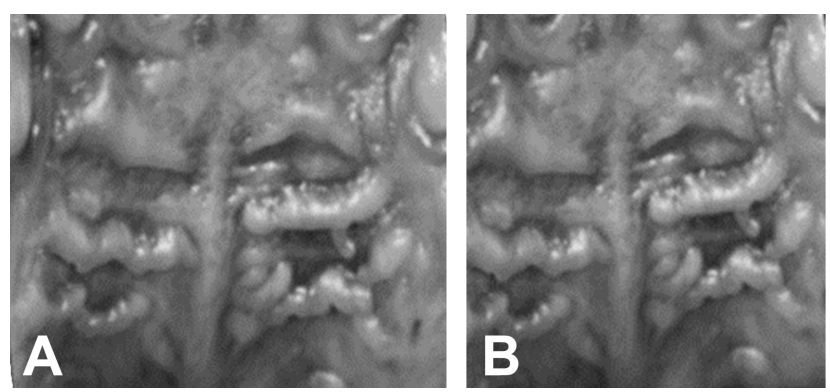

Fig. 5. The 5 degrees and 12 degrees tilted palatal rugae images. (A) $V=5^{\circ}$ (B) $V=12^{\circ}$.
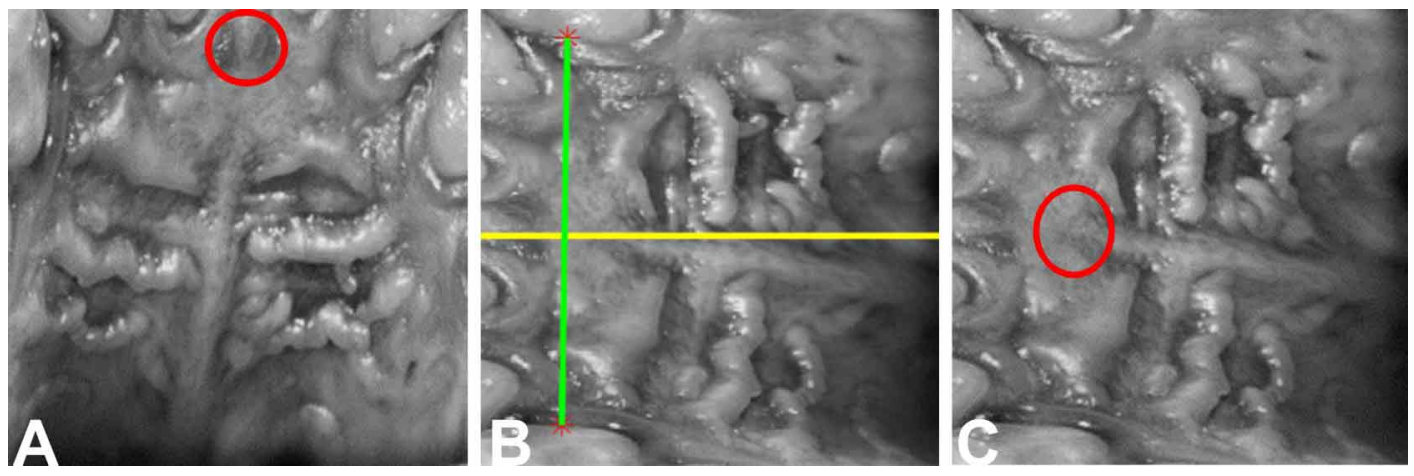

Fig. 4. A schematic diagram of the correction process of a tilted palatal rugae image. (A)Original image (B) Feature point selected image (C) Corrected images. 

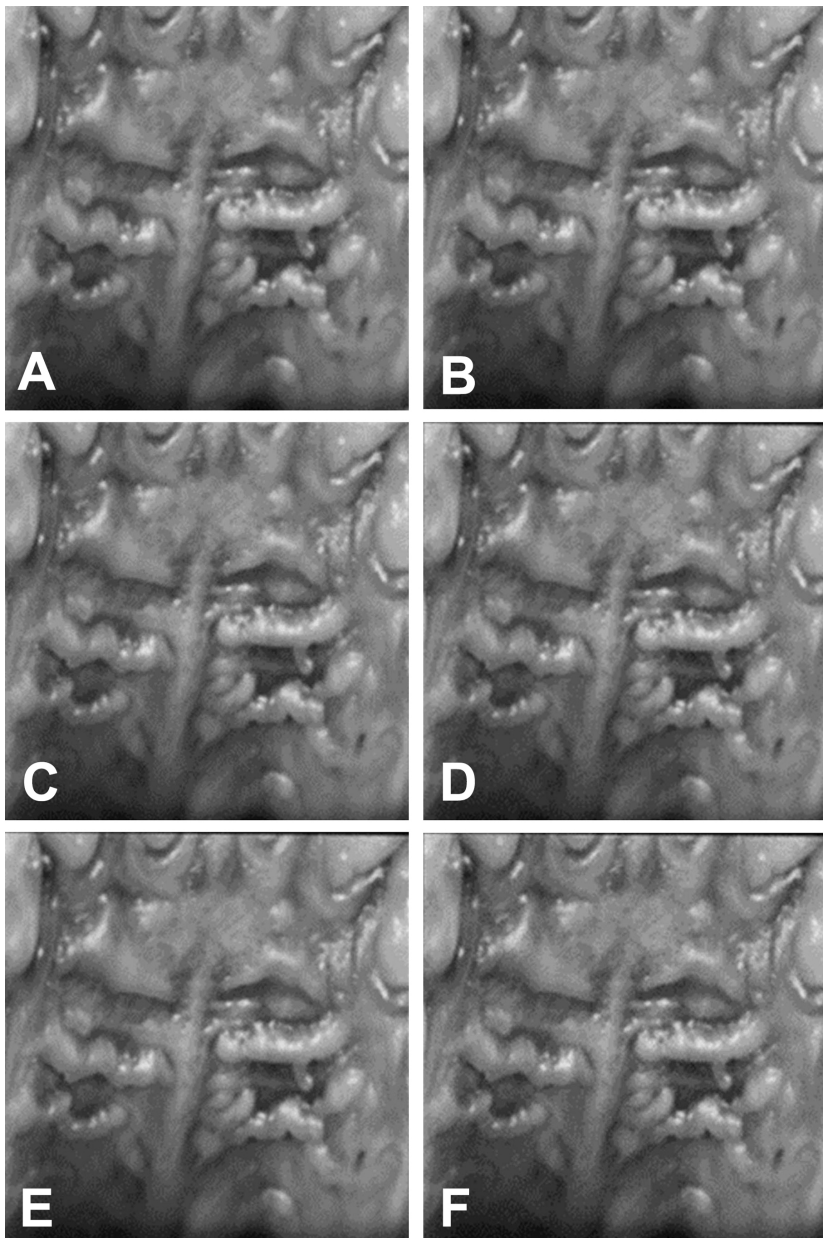

Fig. 6. The six corrected images of 5 degrees tilted palatal rugae image.

(A) The first corrected image. (B) The second corrected image.

(C) The third corrected image. (D) The fourth corrected image.

(E) The fifth corrected image. (F) The sixth corrected image.

\section{RESULTS}

To further objectively evaluate the algorithm, the above two six correction angles are plotted as a line graph (as shown in Figure 8). It can be observed in Figure 8(A) that, when the 5 degrees tilted palatal rugae image are corrected, the first correction is a trial process, which is quite different from the known tilt angle. And with the increase of correction times, the correction angle gradually approaches 5 degrees, and fluctuates in a small range from top to bottom, and the correction angle gradually becomes stable. It can be observed in Figure 8(B) that, when the 12 degrees tilted palatal rugae image are corrected, as the tilt angle increases, the number of corrections approaching the known tilt angle increases, but with the increase of correction times, the correction angle gradually becomes
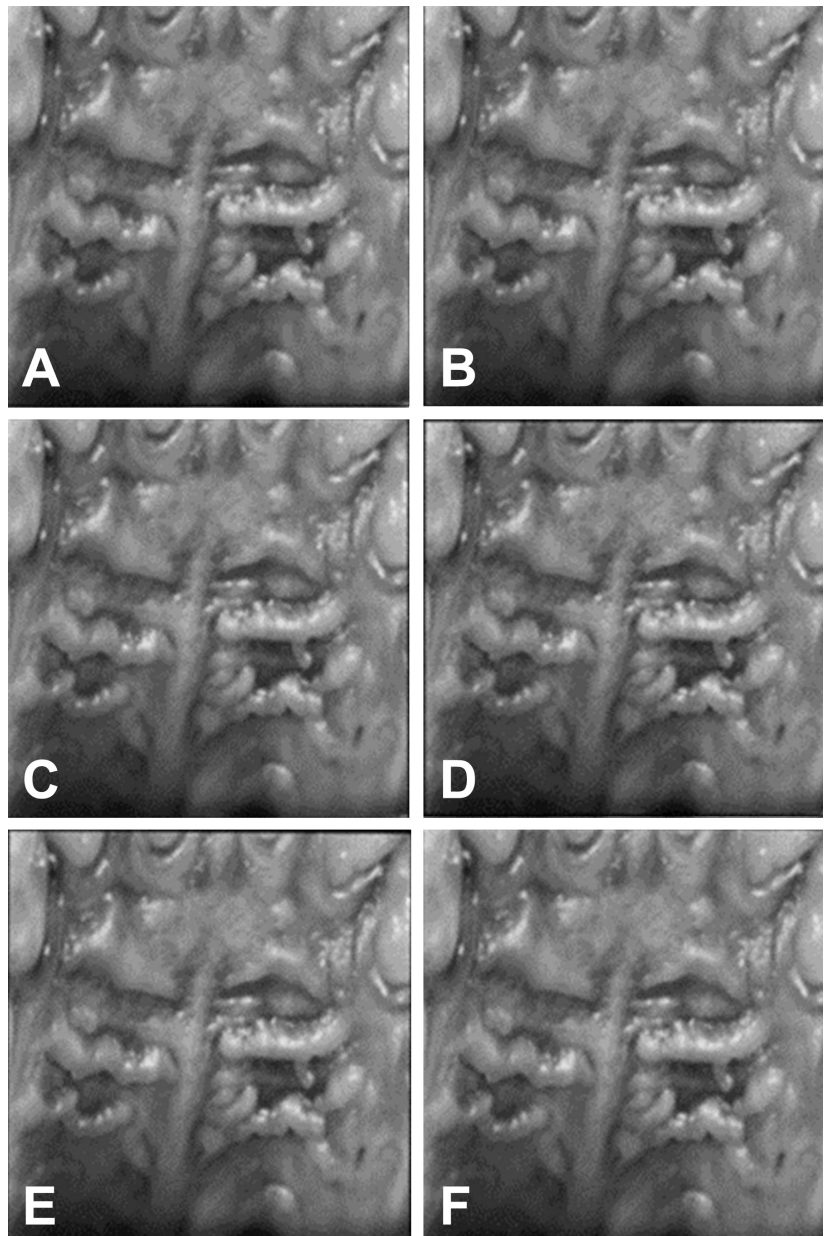

Fig. 7. the six corrected images of 12 degrees tilted palatal rugae image.

(A) The first corrected image. (B) The second corrected image.

(C) The third corrected image. (D) The fourth corrected image.

(E) The fifth corrected image. (F) The sixth corrected image.

stable. It can be seen that the deviation between each correction angle and the known inclination angle is less than one degree, and the correction effect is ideal. The variance of six correction angles is used as a measurement index. The stability of the algorithm is further analyzed and the formula is as follows.

$$
\begin{gathered}
s=\sum_{i=1}^{6}\left(y_{i}-\bar{y}\right)^{2} \\
\bar{y}=\sum_{i=1}^{6} y_{i}
\end{gathered}
$$

where $y_{\mathrm{i}}(\mathrm{i}=1,2, \mathrm{~L}, 6)$ represents the angle of the $i t h$ correction. $y$ is the average value of the 6 correction angles. The data analysis of the correction results is shown in Tables I and II. 
Table I. Analysis of correction results for 5 degrees tilted palatal rugae images.

\begin{tabular}{lcccccc}
\hline Correction time & 1 & 2 & 3 & 4 & 5 & 6 \\
\hline Tilted angle & $5^{\circ}$ & $5^{\circ}$ & $5^{\circ}$ & $5^{\circ}$ & $5^{\circ}$ & $5^{\circ}$ \\
Correction $v$ angle & $4.4387^{\circ}$ & $4.8322^{\circ}$ & $5.0599^{\circ}$ & $5.0624^{\circ}$ & $5.0862^{\circ}$ & $4.9811^{\circ}$ \\
Correction mean & & $4.9166^{\circ}$ & & & & \\
Correction variance & & 0.3230 & & & & \\
\hline
\end{tabular}

Table II. Analysis of correction results for 12 degrees tilted palatal rugae images.

\begin{tabular}{lcccccc}
\hline Correction time & 1 & 2 & 3 & 4 & 5 & 6 \\
\hline Tilted angle & $12^{\circ}$ & $12^{\circ}$ & $12^{\circ}$ & $12^{\circ}$ & $12^{\circ}$ & $12^{\circ}$ \\
Correction $v$ angle & $11.3503^{\circ}$ & $11.5922^{\circ}$ & $11.8150^{\circ}$ & $11.9550^{\circ}$ & $12.0741^{\circ}$ & $12.03^{\circ}$ \\
Correction mean value & & 11.8071 & & & \\
Correction variance & & 0.4116 & & & \\
\hline
\end{tabular}

The results show that the deviation of the correction angle from the actual tilt angle is very small when the two angles are corrected. From the mean value, the difference from the actual angle is not more than one degree. From the point of view of its variance, it can be kept below 0.5. A large number of experimental results show that the algorithm can achieve angle correction with very little error and good stability, and has good robustness.

The results of the comprehensive experiment show that the correction results are ideal and the angle difference between the standard image can be ignored, and the stability of the algorithm is further demonstrated.

\section{DISCUSSION}

With the rapid development of modern forensic medicine and artificial intelligence technology, many scholars

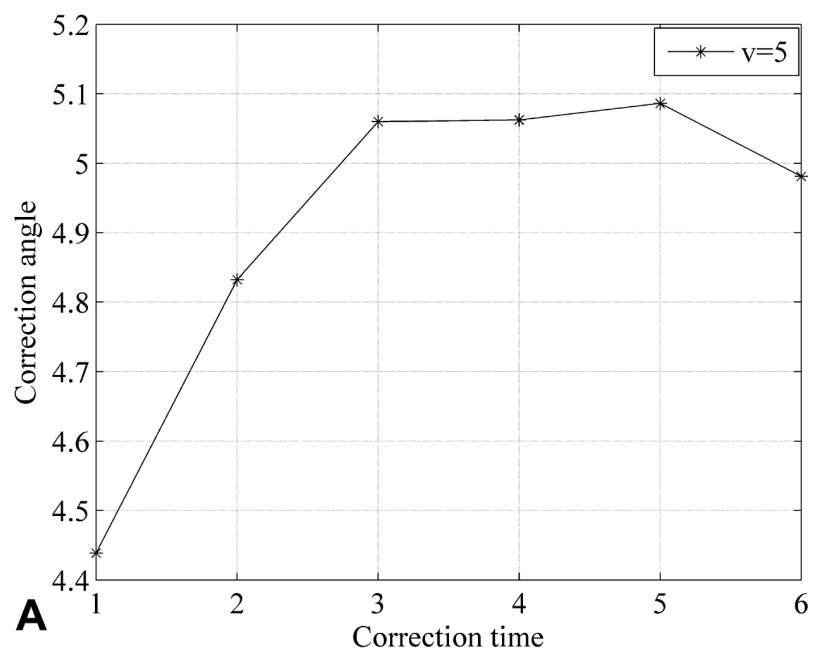

have done a lot of research on some important identity characteristic index (Limson \& Julian, 2004; Gondivkar et al., 2011), such as teeth, craniofacial morphology, fingerprints, palmprint, DNA, etc. But sometimes due to the particularity of application environment, there are still some problems in the traditional identification technology. On one hand, because that the anatomical position of fingerprints, palm prints, craniofacial and other features is located on the surface of the human body, these characteristic indexes can easily be affected by environmental factors such as fire, chemical corrosion or external trauma, resulting in lack of information. In major disasters and terrorist attacks, environmental and economic factors often limit the achievement of DNA testing for large-scale victims. On the other hand, biometrics such as face recognition, fingerprint recognition, and iris recognition are vulnerable to attacks such as fake fingerprints, facial facelifts, and dental surgery. Therefore, the study of human characteristics indicators that are not easily destroyed and forged and cost-effective can provide a new means for forensic identification. The shape

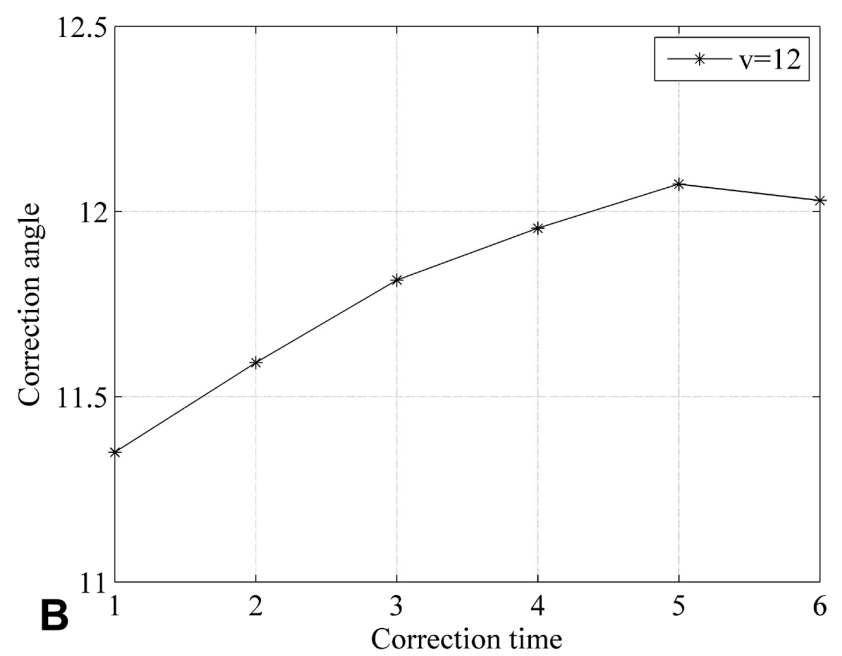

Fig. 8. The curves of the relationship between correction times and the correction angles. (A) $v=5^{\circ}(B) v=12^{\circ}$ 
of palatal rugae, like fingerprints and lip lines, never changes during a person's life, and even disease, trauma or chemical corrosion will not change the shape and position of palatal rugae. The three characteristics of palatal rugae, such as stability, diversity and widespread existence in human body, make palatal rugae as a test target for the forensic identification (Shukla et al., 2011; dos Santos et al., 2011; Taneva et al., 2015).

The collection of palatal rugae is usually carried out in two ways: the first method, that is, using optical principle, the palatal rugae were reflected into the reflective lenses, and then a digital camera is used to photograph the palatal rugae in the lens; the second method, that is, through the occlusion, the plaster model of the human oral maxilla is made, and the palatal rugae is depicted artificially, and then using the camera to shoot the plaster model, the palatal rugae image can be obtained. The first method is not only simple, but also easy to accept, and can be collected in many angles and omni-directional. Compared with the second method, no useful details are lost due to manual operations. Therefore, by comparison, this study used the digital images of palatal rugae directly collected by a digital SLR camera (Canon EOS 300D) and a special orthodontic reflector. Because the acquisition of images will cause the appearance of a lot of unnecessary information, such as teeth, tongue, etc., the image processing software Photoshop can be used to perform a preliminary cropping process, roughly remove most of the irrelevant background.

The idea of the tilted image correction algorithm proposed in this study is, defining the standard state of the image based on image characteristics, and determining the tilt angle and tilt direction of the current image by the positional relationship between the selected feature points and the predetermined points, and then using mathematics to get the angle of rotation and rotate the image to the standard state. In order to facilitate the observation of the angle between the feature point connection line and the horizontal direction, when setting the predetermined point, the predetermined point is set to $(1, n / 2)$ and $(m / 2, n / 2)$ (where $m$ is the width of the palatal rugae image, and $n$ is the height of the palatal rugae image), that is, the horizontal line is based on the height of the image. Secondly, observing most of the acquired images, considering the number of teeth appearing in the image, the geometric center of the edge of the third tooth around the incisive papilla is selected as the feature point. In this paper, a tilted image correction algorithm based on direction vector is proposed. The experimental results show that, when using the algorithm to correct tilted palatal rugae images from multiple acquisition angles, the algorithm has a very stable correction effect and shows strong robustness.
The purpose of this study is to improve the accuracy of palatal rugae image recognition by studying the image correction method in the palatal rugae image preprocessing system. What needs to be further studied is how the selection rules of the feature points and the standard state of the image should be set when the image is not included in the tooth area or the palate area is unsymmetrical.

SHANGGUAN, H.; LI, B.; ZHANG, X.; JI, X. X.; KWON, T. G. \& WU, X. P. Investigación sobre el método de corrección de la morfología de las rugas palatinas en sistema digital de identificación forense. Int. J. Morphol., 37(1):324-330, 2019.

RESUMEN: Las rugas palatinas son tejidos blandos irregulares, que se ubican en el tercio frontal del paladar duro y se distribuyen asimétricamente desde la sutura mediana hacia los lados. La diferencia, la estabilidad y las características extensivas de la morfología de las rugas palatinas la han convertido gradualmente en un indicador característico de la identificación forense. Sin embargo, un sistema de identificación de rugas palatinas digitales maduras todavía no se ha establecido en la actualidad. La extracción de características es la premisa del reconocimiento de imágenes de las rugas palatinas. Para obtener información sobre las características de las rugas palatinas en todas las direcciones, y mejorar la confiabilidad de la identificación forense, es necesario recopilar imágenes de las rugas palatinas desde una pluralidad de ángulos diferentes. Cuando las imágenes recogidas se envían al sistema de reconocimiento, la diversidad de ángulos a menudo causará problemas como el reconocimiento de errores. Si las imágenes inclinadas no se giran correctamente, la identificación forense se enfrentará a muchas dificultades. Para resolver el problema del sesgo de la imagen causado por la diversidad del ángulo de adquisición, en este documento se propuso un algoritmo basado en el vector de orientación para corregir las imágenes de las arrugas palatinas inclinadas. En primer lugar, se establecieron los criterios para la imagen de las rugas palatinas estándar, y las reglas de selección para los puntos de características. En segundo lugar, se determinaron puntos de características según las reglas, y se ajustaron dos líneas y encontrar la dirección del vector. Finalmente, para obtener las imágenes corregidas, las imágenes inclinadas se giraron según el ángulo determinado por la dirección de dos vectores. Los resultados de la simulación muestran que el algoritmo propuesto puede corregir las imágenes de rugas palatinas inclinadas recopiladas desde diferentes ángulos y tiene una gran robustez.

PALABRAS CLAVE: Odontología forense; Rugas palatinas; Identificación forense; Vector de direccion Corrección de imagen.

\section{REFERENCES}

Bharath, S. T.; Kumar, G. R.; Dhanapal, R. \& Saraswathi, T. Sex determination by discriminant function analysis of palatal rugae from a population of coastal Andhra. J. Forensic Dent. Sci., 3(2):58-62, 2011. 
Braga, S. \& Caldas, I. M. Study of palatal rugae pattern following orthodontic treatment. Aust. J. Forensic Sci., 48(3):305-11, 2016.

Clarke, R. Human identification in information systems: management challenges and public policy issues. Inf. Technol. People., 7(4):6-37, 1994.

dos Santos, K. C.; Fernandes, C. M. S. \& da Costa Serra, M. Evaluation of a digital methodology for human identification using palatal rugoscopy. Braz. J. Oral Sci., 10(3):199-203, 2011.

Gadicherla, P.; Saini, D. \& Bhaskar, M. Palatal rugae pattern: An aid for sex identification. J. Forensic Dent. Sci., 9(1):48, 2017.

Gautam, N.; Patil, S. G.; Krishna, R. G.; Agastya, H.; Mushtaq, L. \& Kumar, $\mathrm{K}$. V. Association of palatal rugae pattern in gender identification: an exploratory study. J. Contemp. Dent. Pract., 18(6):470-3, 2017.

Gondivkar, S. M.; Patel, S.; Gadbail, A. R.; Gaikwad, R. N.; Chole, R. \& Parikh, R. V. Morphological study of the palatal rugae in western Indian population. J. Forensic Leg. Med., 18(7):310-2, 2011.

Indira, A. P.; Gupta, M. \& David, M. P. Rugoscopy for establishing individuality. Indian J. Dent. Adv., 3(1):427-32, 2011.

Jain, A. K.; Nandakumar, K. \& Ross, A. 50 years of biometric research: Accomplishments, challenges, and opportunities. Pattern Recognit. Lett., 79(1):80-105, 2016.

Jain, A.; Hong, L. \& Pankanti, S. Biometric identification. Commun. ACM, 43(2):90-8, 2000.

Li, B.; Wu, X. P.; Feng, Y.; Wang, Y. J. \& Liu, H. C. Palatal rugae for the construction of forensic identification. Int. J. Morphol., 32(2):546-50, 2014.

Limson, K. S. \& Julian, R. Computerized recording of the palatal rugae pattern and an evaluation of its application in forensic identification. $J$. Forensic Odontostomatol., 22(1):1-4, 2004.

Mittal, L.; Narang, R. \& Saha, R. Palatal rugoscopy. Establishing identity. Indian J. Contemp. Dent., 1(1):58-61, 2013.

Shukla, D.; Chowdhry, A.; Bablani, D.; Jain, P. \& Thapar, R. Establishing the reliability of palatal rugae pattern in individual identification (following orthodontic treatment). J. Forensic Odontostomatol., 29(1):20-9, 2011.

Syed, S.; Alshahrani, I.; Alshahrani, A.; Togoo, R. A.; Luqman, M. \& Dawasaz, A. A. Conversion of palatal rugae pattern to scanable Quick Response code in an Arabian population. J. Dent. Sci, 11(3):253-60, 2016.

Taneva, E. D.; Johnson, A.; Viana, G. \& Evans, C. A. 3D evaluation of palatal rugae for human identification using digital study models. $J$. Forensic Dent. Sci., 7(3):244-52, 2015.

Taneva, E.; Evans, C. \& Viana, G. 3D evaluation of palatal rugae in identical twins. Case Rep. Dent., 2017:2648312, 2017.

Wu, X. P.; Han, J. N.; Fen, P.; Wang, Y. J. \& Bing, L. Application of palatal rugae morphology in forensic identification. Int. J. Morphol., 34(2):510$3,2016$.

\section{Corresponding author:}

Hong Shangguan

School of Electronic Information Engineering

Taiyuan University of Science and Technology

No 66 Waliu Road, Waibailin District

Taiyuan, Shanxi Province 030024

CHINA

Email: shangguan_hong01@163.com

Received: 31-07-2018

Accepted: 16-10-2018 